\title{
Soaking Seeds with Exogenous Melatonin Improve Photosynthetic Characteristics of Radish under Aluminum Stress
}

\author{
Yi Tang ${ }^{1, a}$, Fengyun Lei ${ }^{2, b}$, Enze Zhang ${ }^{2, \mathrm{c}}$ and Huanxiu $\mathrm{Li}^{1, \mathrm{~d}}{ }^{*}$ \\ ${ }^{1}$ Institute of Pomology and Olericulture, Sichuan Agricultural University, Chengdu, Sichuan, China \\ ${ }^{2}$ College of Horticulture, Sichuan Agricultural University, Chengdu, Sichuan, China

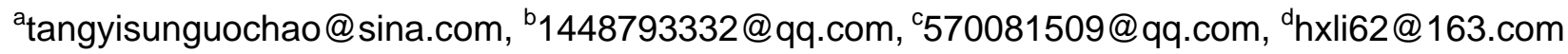 \\ *Corresponding author
}

Keywords: Melatonin; Soaking seeds; Radish; Photosynthetic characteristics

Abstract. A pot experiment was conducted to study the effects of exogenous melatonin (MT) on photosynthetic characteristics of radish under aluminum (Al) stress. Five treatments were used in the experiment: seeds were soaked with $0(\mathrm{CK}), 50,100,150$ and $200 \mu \mathrm{mol} \cdot \mathrm{L}^{-1}$ concentrations of melatonin solution. The results showed that melatonin enhanced net photosynthetic rate $(\mathrm{Pn})$ and of radish significantly. Compared with $\mathrm{CK}$, low concentration of MT enhanced transpiration rate $(\mathrm{Tr})$ and stomatal conductance (Gs) of radish under Al stress. However when concentration of MT is too high, Tr and Gs of radish decreased. The result of light use efficiency (LUE) and water use efficiency (WUE) were the same as $\mathrm{Pn}$. Soaking different concentrations of melatonin on radish under aluminum stress has not significant effect on $\mathrm{CO}_{2}$ concentration of intercellular (Ci). Therefore, melatonin could use to enhance the photosynthetic ability of radish, which would help to improve the adaptability of radish, and the best concentration of melatonin was $100 \mu \mathrm{mol} \cdot \mathrm{L}-1$.

\section{Introduction}

In recent years, with the accelerated process of industrialization, frequently disturbed by human activity and the impact of a variety of other factors, soil acidification became prominent problem increasingly [1]. There are large areas of acid soils in South China, and aluminum toxicity is considered as major obstacle factor restricting crop production in acidic soils [2]. It was found that aluminum can hinder the synthesis of chlorophyll and inhibit growth of plant [3]. Studies have shown that exogenous organic acids can effectively relieve aluminum toxicity of rapeseed and soybean[4,5].

Melatonin (MT) is the strongest antioxidant scavenger of free radical, which can alleviate the damage caused by external environment [6].

In recent years, many studies have found that melatonin can alleviate abiotic stress harm to the plant, reduce the damage of low temperature and high temperature on plants, but also significantly increase the resistance of plants under sodium chloride stress [7-9]. Toxicity of aluminum chloride and sodium chloride to plants are similar, however, there is no study on whether melatonin can increase the resistance of plants under aluminum chloride stress.

Radish (Raphanus sativus L.) is rich in nutrients, has good food value and medicinal value, are widely cultivated throughout China[10].

In this study, we used different concentrations of melatonin to soak radish seeds for the purpose of screening the influence of melatonin on photosynthetic characteristics of radish under aluminum stress.

\section{Materials and Methods}

Materials. The experiments were conducted at Sichuan Agricultural University $\left(30^{\circ} 42^{\prime} \mathrm{N}, 103^{\circ} 51^{\prime}\right.$ E), Wenjiang, China. The seeds of radish named red skin radish were harvested in 2014 and purchased from Chengdu, China. All chemicals used in experiments were of analytical grade. Melatonin was purchased from Sigma-Aldrich (St. Louis, MO, USA). 
Experimental Design. Selected the same size and full of radish seeds, placed in five test tubes, soaked with $0(\mathrm{CK}), 50,100,150,200 \mu \mathrm{mol} \cdot \mathrm{L}^{-1}$ concentrations of melatonin solution for $24 \mathrm{~h}$, added $50 \mathrm{~mL}$ melatonin solution in every test tubes, respectively. There were 20 seeds in each test tube. After germination, seeds were planted in nutrition pot filled with vermiculite and perlite, the pot was ten centimeters in diameter and height. Each treatment consisted of 10 pots with one plant per pot.

When the cotyledons growed, seedlings were irrigated with $20 \mathrm{ml}$ Hoagland nutrient solution containing $50 \mu \mathrm{mol} \cdot \mathrm{L}^{-1}$ concentrations of aluminum chloride every three day, watering according to weather conditions, until the experiment finishing. Positions of the pots were randomly changed daily to minimize positional effects. 45 days after treatment, the photosynthesis of each plant was determined by using LI-6400 portable photosynthesis meter (LI-COR Inc., USA). The photosynthetic parameters of the photosynthesis meter were manual control $\mathrm{CO}_{2}$ concentration $400 \mu \mathrm{mol} \cdot \mathrm{CO}_{2} \mathrm{~mol}^{-1}$, temperature $25^{\circ} \mathrm{C}$, light intensity $1200 \mu \mathrm{mol} \mathrm{m}{ }^{-2} \cdot \mathrm{s}^{-1}$. The determination of photosynthetic parameters were net photosynthetic rate $(\mathrm{Pn})$, transpiration rate $(\mathrm{Tr})$, stomatal conductance $(\mathrm{Gs})$ and $\mathrm{CO}_{2}$ concentration of intercellular $(\mathrm{Ci})$, and each treatment was repeated three times. Water use efficiency $(\mathrm{WUE})=$ net photosynthetic rate $(\mathrm{Pn}) /$ transpiration rate $(\mathrm{Tr})$, Light use efficiency $(\mathrm{LUE})=$ net photosynthetic rate $(\mathrm{Pn}) /$ light intensity.

Statistic analyses. Statistical analyses were performed using SPSS 13.0 statistical software (IBM, Chicago, IL, USA). Data were analyzed by one-way ANOVA with least significant difference (LSD) at a $5 \%$ confidence level.

\section{Results and Discussion}

Net Photosynthetic Rate (Pn). Compared with CK, melatonin enhanced Pn of radish under Al stress significantly, and the Pn of radish was increased with the increasing of MT concentration (Fig. 1). When the concentration of MT were 50, 150 and $200 \mu \mathrm{mol} \cdot \mathrm{L}^{-1}$, these treatments enhanced Pn of radish by $21.75 \%(p<0.05), 25.35 \%(p<0.05)$ and $3.25 \%(p>0.05)$ respectively, compared with CK. When the concentration of MT was $100 \mu \mathrm{mol} \cdot \mathrm{L}^{-1}$, Pn of radish reached the highest, and increased by $44.30 \%(p<0.05)$. In this study, it was illustrated that melatonin can alleviate the $\mathrm{Al}$ stress and improve photosynthetic capacity of radish seedlings.

Transpiration Rate (Tr). Melatonin increased the Tr of radish (Fig. 2). Compared with CK, When the concentration of MT were 50 and $150 \mu \mathrm{mol} \cdot \mathrm{L}^{-1}$, these treatments enhanced $\mathrm{Tr}$ of radish by $19.33 \%$ $(p>0.05)$ and $17.72 \%(p>0.05)$ respectively. When the concentration of MT was $100 \mu \mathrm{mol} \cdot \mathrm{L}^{-1}, \mathrm{Tr}$ of radish reached the highest, and increased by $32.84 \%(p<0.05)$. However when concentration of MT is too high, Tr of radish decreased by $0.39 \%(p>0.05)$ compared with CK. It was showed that low concentration of melatonin can alleviate the Al stress of radish seedlings.

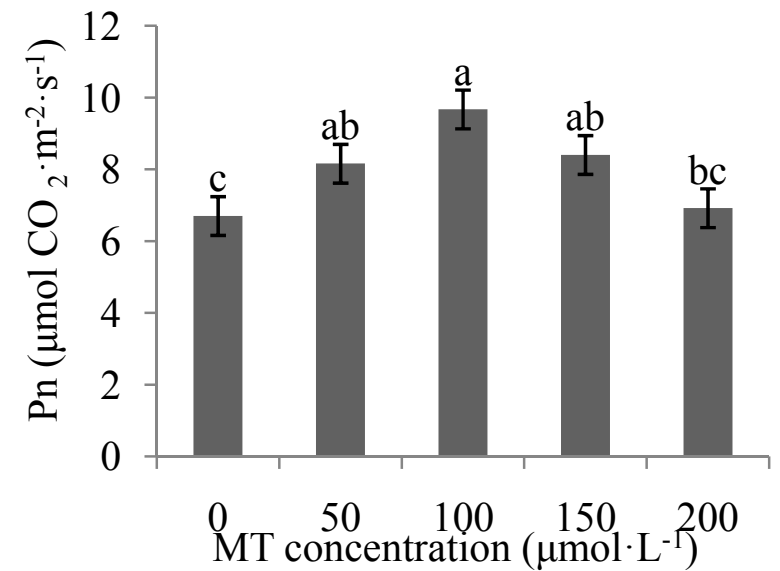

Fig. 1 Pn of MT soaked radish

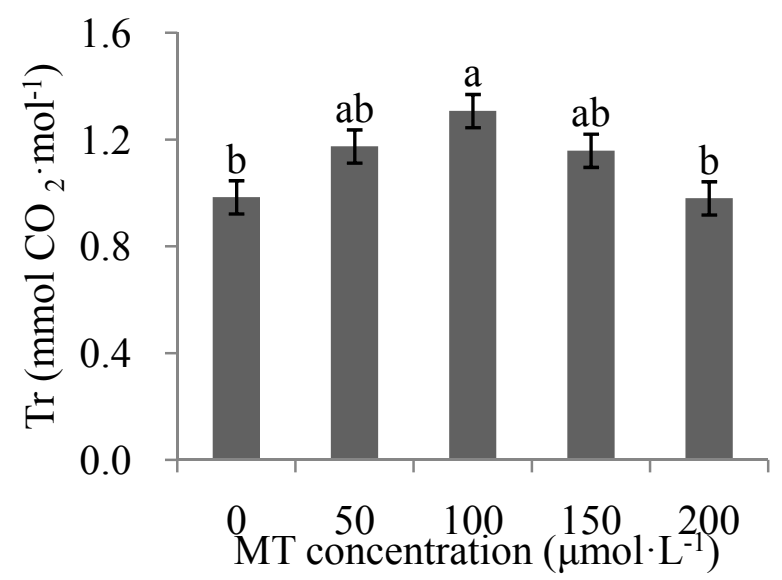

Fig. 2 Tr of MT soaked radish 
Water Use Efficiency (WUE). Compared with CK, When the concentration of MT were 50,150 and $200 \mu \mathrm{mol} \cdot \mathrm{L}^{-1}$, these treatments enhanced WUE of radish by $2.02 \%(p>0.05), 6.48 \%(p>0.05)$ and $3.66 \%(p>0.05)$ respectively. When the concentration of MT was $100 \mu \mathrm{mol} \cdot \mathrm{L}^{-1}$, WUE of radish reached the highest, and increased by $8.63 \%(p<0.05)$. It was showed that suitable concentration of melatonin can alleviate the Al stress.

Light Use Efficiency (LUE). Melatonin increased the LUE of radish with the increasing of MT concentration under Al stress (Fig. 4). When the concentration of MT were 50, 150 and $200 \mu \mathrm{mol} \cdot \mathrm{L}^{-1}$, these treatments enhanced LUE of radish by $21.75 \%(p<0.05), 25.35 \%(p<0.05)$ and $3.25 \%(p>$ $0.05)$ respectively, compared with CK. When the concentration of MT was $100 \mu \mathrm{mol} \cdot \mathrm{L}^{-1}$, LUE of radish reached the highest, and increased by $44.30 \%(p<0.05)$. It was showed that melatonin can alleviate the $\mathrm{Al}$ stress of radish seedlings.

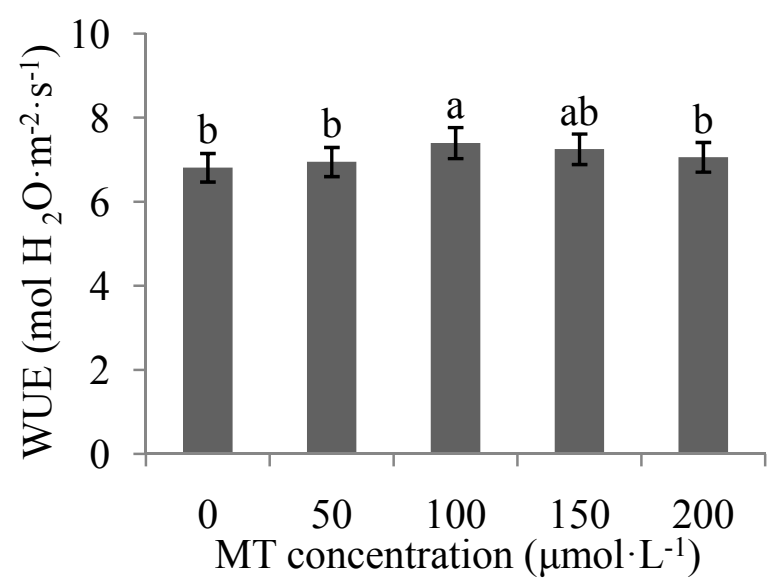

Fig. 3 WUE of MT soaked radish

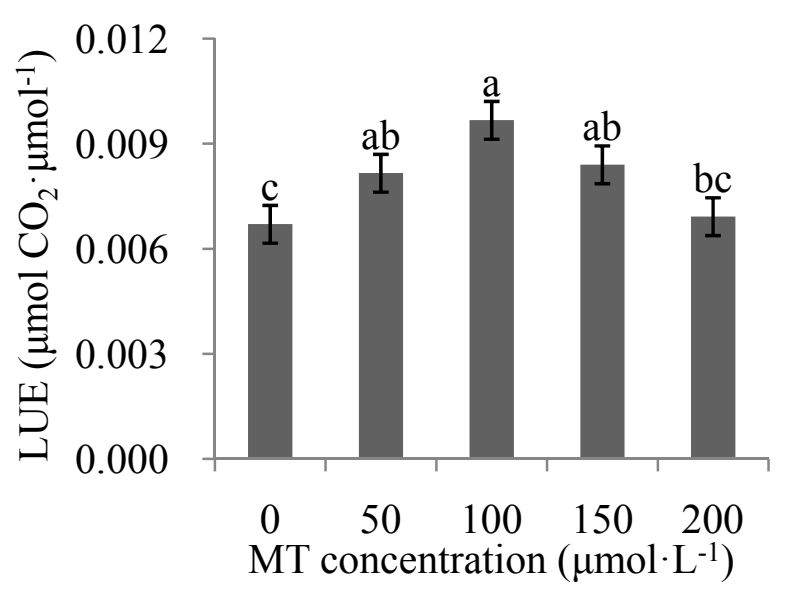

Fig. 4 LUE of MT soaked radish

Stomatal Conductance (Gs). After soaked with melatonin, Gs of radish increased (Fig. 5). Compared with CK, When the concentration of MT were 50,100 and $150 \mu \mathrm{mol} \cdot \mathrm{L}^{-1}$, these treatments enhanced Gs of radish by $6.23 \%(p>0.05), 42.79 \%(p>0.05)$ and $11.30 \%(p>0.05)$ respectively. When concentration of MT is too high $\left(200 \mu \mathrm{mol} \cdot \mathrm{L}^{-1}\right)$, Gs of radish decreased by $21.50 \%(p>0.05)$ compared with CK. However, treatments of different concentrations of MT were not significant. It is illustrated that the effect of melatonin on Gs was not obvious.

$\mathbf{C O}_{2}$ Concentration of Intercellular (Ci). Difference between soaked with different concentrations of melatonin were not significant. It is illustrated that the effect on $\mathrm{Ci}$ of melatonin was not obvious.

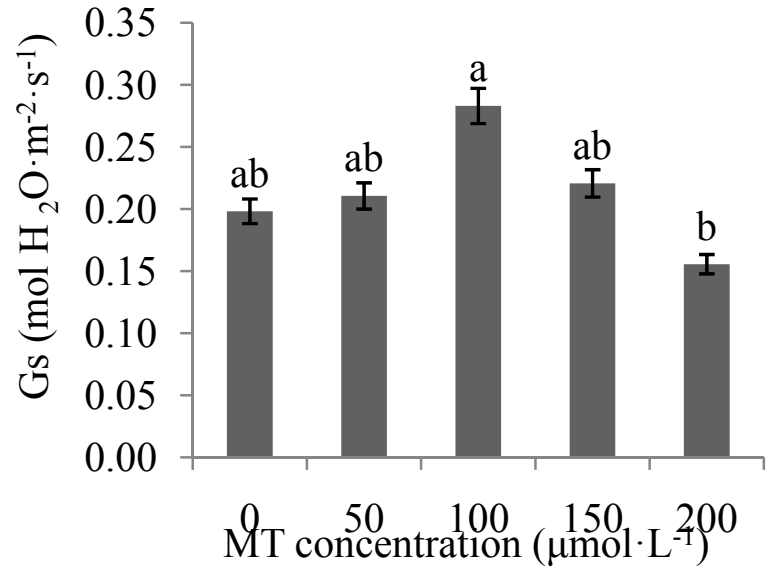

Fig. 5 Gs of MT soaked radish

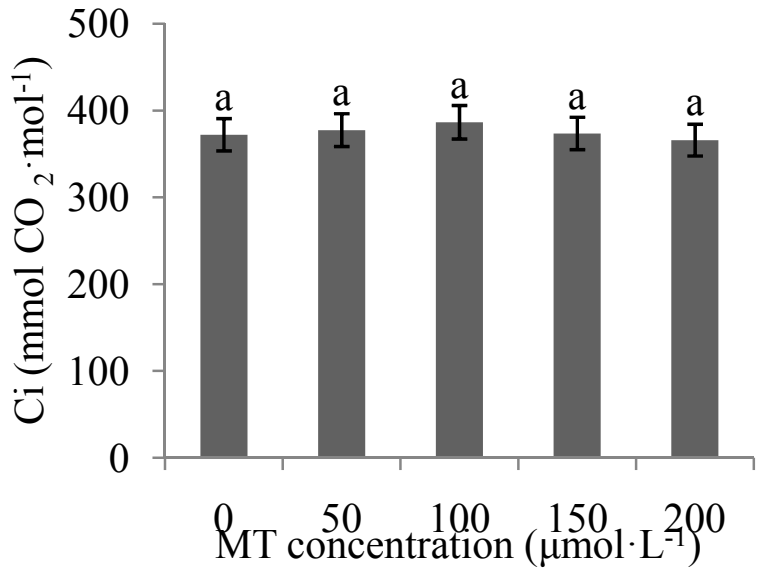

Fig. $6 \mathrm{Ci}$ of MT soaked radish 


\section{Conclusions}

Melatonin can alleviate the Al stress on photosynthetic organ damage and improve photosynthetic capacity of radish seedlings. With the increasing of MT concentration, Pn of radish were enhanced significantly. Compared with CK, low concentration of MT enhanced $\mathrm{Tr}$ and Gs of radish under Al stress. However when concentration of MT is too high, Tr and Gs of radish decreased. The result of LUE and WUE were the same as Pn. Soaking different concentrations of melatonin on radish under aluminum stress has not significant effect on $\mathrm{Ci}$. Therefore, melatonin could use to enhance the photosynthetic ability of radish, which would help to improve the adaptability of radish.

\section{Acknowledgements}

This work was financially supported by the Sichuan Agricultural University "Shuang-Zhi Plan" Foundation.

\section{References}

[1] Z.G. Yuan and J.Yang: Journal of Agriculture Vol. 5 (2015), p.51-55 (In Chinese).

[2] J.H. Weng, L.F. Huang and X.R. Liu: China Environmental Science Vol. 20 (2000), p.501-505 (In Chinese).

[3] Y.X. Zheng, S.T. Jia and Y.P. Zhao: Acta Agriculturae Boreali-Sinica Vol. 30(2015), p.150-156 (In Chinese).

[4] S.Y. Yan and Y. P. Wang: Guangdong Journal of Agricultural Sciences Vol. 40 (2013), p.16-20 (In Chinese).

[5] T.T. Jin and P. Liu: Chinese Journal of Oil Crop Sciences Vol. 28 (2006), p.302-308 (In Chinese).

[6] N. Zhang, H.J. Zhang and R.C. Yang: Chinese Agricultural Science Bulletin Vol. 28 (2012), p.16-20 (In Chinese).

[7] H.Y. Pan, X.Q. Zhang and J. Li: Journal of Northwest University (Natural Sciences Edition) Vol.43 (2013), p.238-242 (In Chinese).

[8] X.D. Xu, Y. Sun and X.Q. Guo: Chinese Journal of Applied Ecology Vol. 21 (2010), p.2580-2586 (In Chinese).

[9] N. Zhang, Q. Jiang and D.B. Li: Journal of China Agricultural University Vol. 19 (2014), p.54-60 (In Chinese).

[10] J.S. Li, R. Yang and X.L. Sui: Acta Agriculturae Boreali-Sinica Vol. 23(2008), p.77-80 (In Chinese). 